\title{
Histopathological findings in the iris of dapsone treated leprosy patients
}

\author{
F Brandt, H M Zhou, Z R Shi, N Rai, L Thuladar, H Pradhan
}

\begin{abstract}
From 43 Nepalese leprosy patients skin smear negative, and treated with dapsone (diamino diphenyl sulphone), and without any sign of active leprosy or iritis, specimens from iridectomy during cataract surgery were studied histopathologically. Of 49 iris specimens only six (12\%) were found to be without any histopathological change. Atrophy of the iris stroma was seen in $63 \%$ and neovascularisation in $6 \%$ of all cases. In $16 \%$ in which the dilator muscle could be detected, it was atrophic, and in $11 \%$ the pigmented epithelium was thinned and atrophic. Cellular inflammatory infiltrations were seen in $88 \%$ of all specimens. They were mostly slight in eyes which before operation had been without posterior synechiae of the iris. In most of the eyes in which posterior synechiae had been present moderate or heavy inflammatory cell infiltrates composed of lymphocytes and plasma cells, often associated with macrophages, neutrophils, or eosinophils, were found. In five iris specimens acid fast bacilli were present. This raises the question whether these can survive systemically despite dapsone chemotherapy in the iris, thus leading to dapsone-resistant leprosy and to recurrent iritis.
\end{abstract}

Iritis is an important complication in patients with leprosy' and also in animals infected with Mycobacterium leprae. ${ }^{23}$ The inflammation of the iris leads to posterior synechiae, atrophy of the iris, ${ }^{4}$ decreased intraocular pressure, ${ }^{5}$ and impairment of sight. ${ }^{6}$

The iritis in leprosy may be caused directly by the presence of the $M$. leprae in the iris or by a reaction to some antigenic substances of the bacilli or to antigen-antibody complexes, even when there is no intact or fragmented bacillus in the iris. An autoimmune type of reaction has also been suggested. The persistent and recurrent inflammation in the iris long after the systemic infection has been treated and the patient's disease has been brought under control is generally well known.

The presence of viable $M$. leprae, an acid fast bacilli (AFB) in the iris, with persistent and recurrent inflammations has been suggested, but till now without any definite proof. Whether living AFB remain in the eyeball after the lesions of the skin have been cured and the skin smear has become negative, and whether the recurrent iritis is the result of persistence or increase of these bacteria intraocularly, are questions that need elucidation.

The purpose of this study was to examine histologically iris specimens taken from dapsone treated, skin-smear negative, inactive leprosy patients from Nepal to look for histopathological changes and to search for AFB.

Material and methods

The clinical data were gathered from 43 Nepalese patients with leprosy. They included age, sex, duration of disease, type of leprosy, and findings in the anterior segment (lagophthalmus, corneal opacity, and posterior synechiae). The disease itself was classified according to the system of Ridley and Jopling ${ }^{7}$ as modified by Leiker. ${ }^{8}$ Tuberculosis was not diagnosed in any patient. All had received dapsone for many years and had become clinically inactive. From 49 eyes the iridectomy specimen was taken during cataract extraction. All specimens were fixed in $5 \%$ formalin and embedded in paraffin, and cut sections were stained with haematoxylin and eosin ( $\mathrm{H}$ and $\mathrm{E})$, periodic acid Schiff (PAS), modified Fite Faraco (after depigmentation), Gram, Giemsa, reticulum, and amyloid stains. The severity of the atrophic changes and the amount of inflammatory cell infiltrates in the iris, as well as the grade of the existing AFB, were classified in three grades: slight $(+)$, moderate $(++)$, and heavy $(+++)$. The existence of AFB was determined and noted in the preparation. As a control group for analysis another 33 iridectomy specimens were taken from nonleprosy Nepalese patients of comparable age and sex.

\section{Results}

CLINICAL FINDINGS

Most of the patients were over 40 , had suffered from leprosy for more than 20 years, and were borderline in type. Lagophthalmus was found in $29 \%$, corneal opacity in $47 \%$, and posterior synechiae in $57 \%$ of all the patients (Table I).

\section{HISTOPATHOLOGICAL FINDINGS}

There was mild to severe atrophy of the iris stroma in 31 cases $(63 \%)$. The branches of the stroma chromatophore cells were either shortened or had disappeared (Fig 1). In the most severe cases fibrotic tissue was increased and the number of blood vessels decreased. In some cases the stroma had completely turned into a mass of fibrotic tissue. But in many the atrophic change was not seen throughout the specimen. In one case the fibrotic tissue formed in the iris extended backwards and outwards, merging with the fibrotic membrane formed behind the posterior surface of the iris (Fig 2).

In five cases $(10 \%)$ an increased number of blood vessels was seen in the stroma, while in 


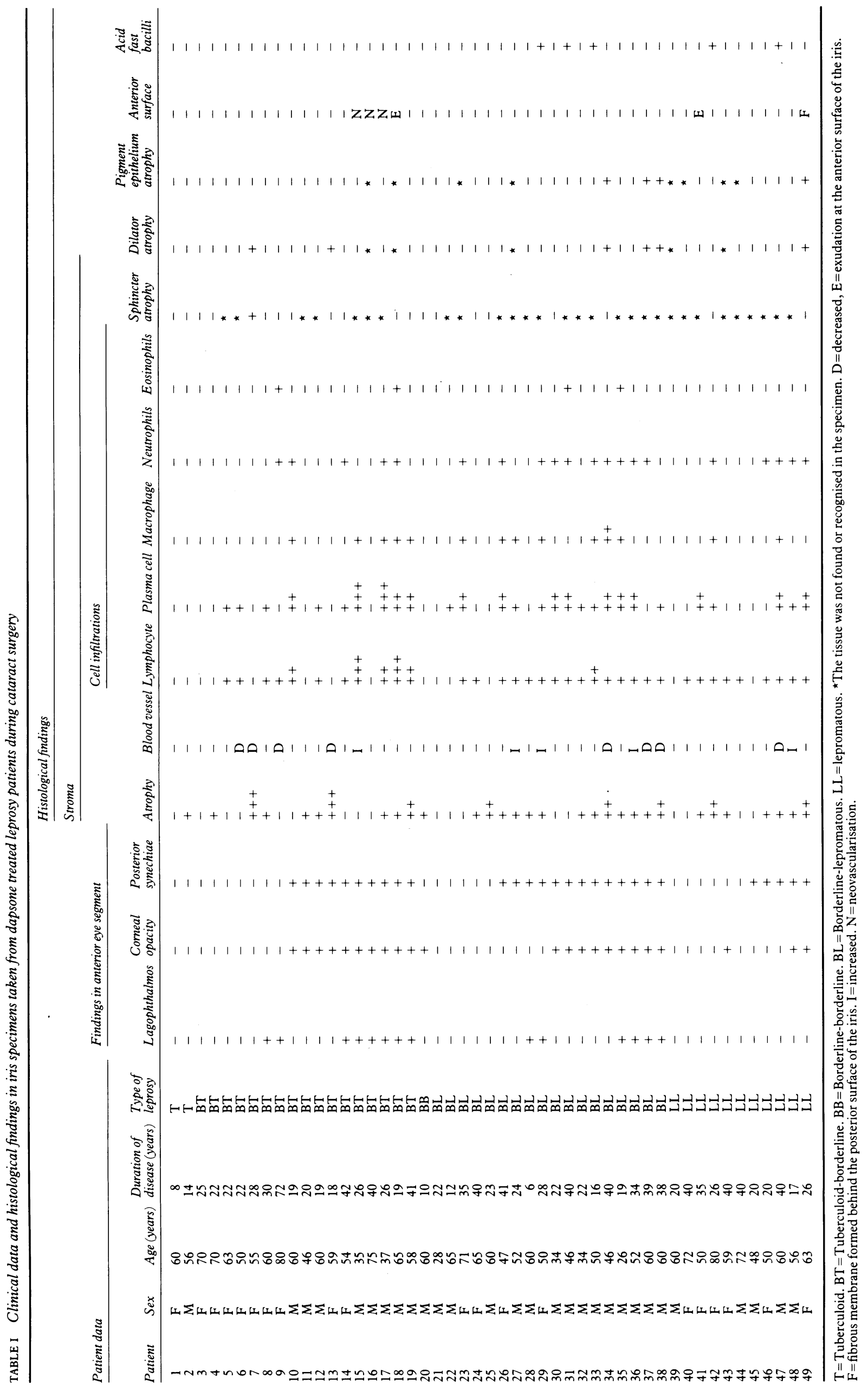




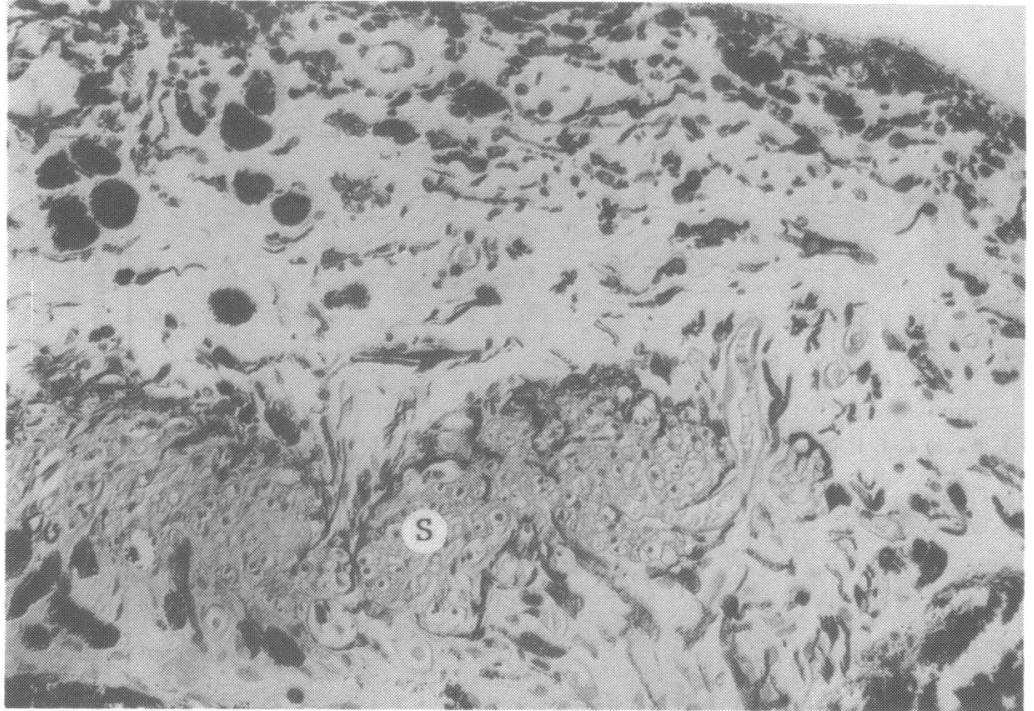

Figure 1: Branches of many stroma cells decreased in number or vanished. The inflammatory cell infiltration is slight. The sphincter muscle $(S)$ seems to be intact. ( $H$ and $E, \times 332$.)

eight cases $(16 \%)$ the number was decreased. In 36 cases $(73 \%)$ there were various amounts of lymphocytes and plasma cells in the stroma, sometimes accompanied by macrophages, neutrophils, and eosinophils (Figs 3, 4) and large Russell's bodies (Fig 5), of which the diameter sometimes exceeded up to 40 micra among the plasma cells. Cellular exudates were attached to the anterior surface of the iris in two cases $(4 \%)$, and in three cases $(6 \%)$ proliferated capillaries were protruding from the anterior surface (Fig 6).

The dilator muscles were atrophic (Fig 7) in six of those 44 cases in which the muscle was seen (14\%). The pigment epithelium was seen in 41 cases, and was thinned and atrophic in four cases $(10 \%)$.

In three iris specimens one or several bacilli were seen in the stroma cells or in the stroma itself. In a fourth case several bacilli were found in the wall of a blood vessel (Fig 8), and in the fifth specimen large amounts of AFB were found throughout the entire iris (Fig 9), mostly within the stroma and the infiltrating cells (Table I).

In one-third of the cases (11/33) in the control group of patients without leprosy the branches of the melanin-containing stroma cells were shortened. The iris showed no atrophy. In four cases there were lymphocytes, plasma cells, and neutrophil infiltrations, but all in slight degree. No AFB was found.

Figure 2: The fibrous tissue in the iris is increased. The adhesion to the lens capsule is obvious. The sphincter muscle $(S)$ is infiltrated by some cells. ( $H$ and $E, \times 60$.)

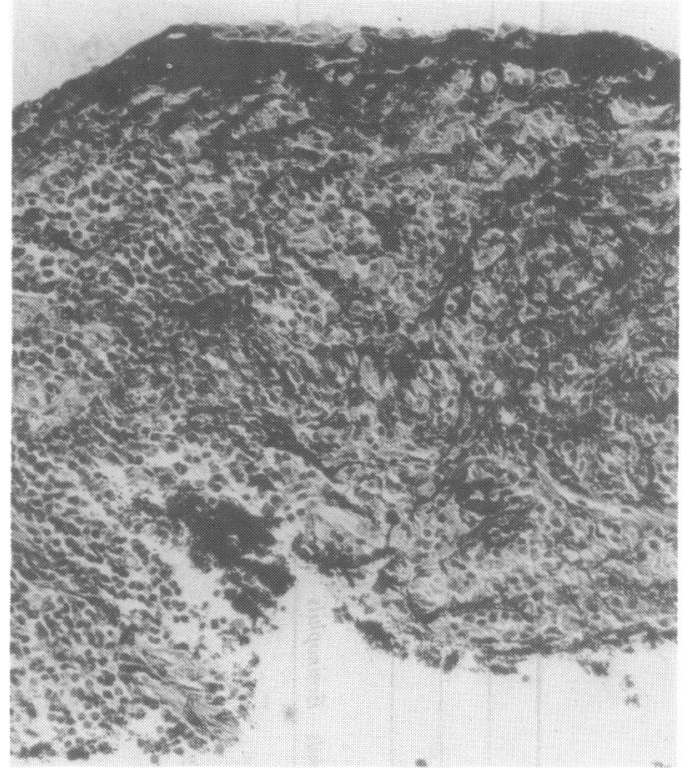

Figure 3: Large amount of inflammatory cells infiltrate the stroma of iris. ( $H$ and $E, \times 78$.)

\section{Discussion}

In the eyes of Nepalese leprosy patients posterior synechiae are often seen in 'advanced cases' in the leprosarium,,${ }^{90}$ and less often but not rarely, in outpatients examined in the leprosy clinics. ${ }^{11} 12$ Often not only had posterior synechiae developed after iritis but also complicated cataract and blindness had done so..$^{1314}$ All the 49 iris specimens were obtained during cataract surgery from leprous patients who were found to be negative to a skin smear test and when there were no clinical signs of active iritis. Histological studies of the iris specimens showed no correlation between the severity of histological changes in the tissue and the duration of disease in each individual, nor in the differences in age or sex of the patients.

A significant difference could be seen in the tissue histology between those showing only lagophthalmus/corneal opacity and those having signs of previous iritis, and posterior synechiae in particular. Whereas in the former only slight histological changes were seen for the most part, the latter mostly showed moderate to heavy signs of inflammation. Lymphocytes, mast cells, and even Russell's bodies were frequently seen. The Russell's bodies were larger in our specimens than those usually found in other inflammatory conditions. The presence of macrophages and neutrophils was practically restricted to specimens obtained from eyes having posterior synechiae preoperatively. It is likely that postoperative iritis may recur in those leprosy patients following cataract extraction, and these eyes should therefore be watched most carefully. ${ }^{15} 16$

The atrophy of dilator muscles of the iris that was seen in the specimens may be due to neuroparalysis as a sequel to the chronic and recurrent inflammatory processes in leprous patients. The early atrophic changes in the iris dilator muscles may not be easily discovered under the light microscope, especially when the bleaching of the melanin granules in the tissue has not been complete. 


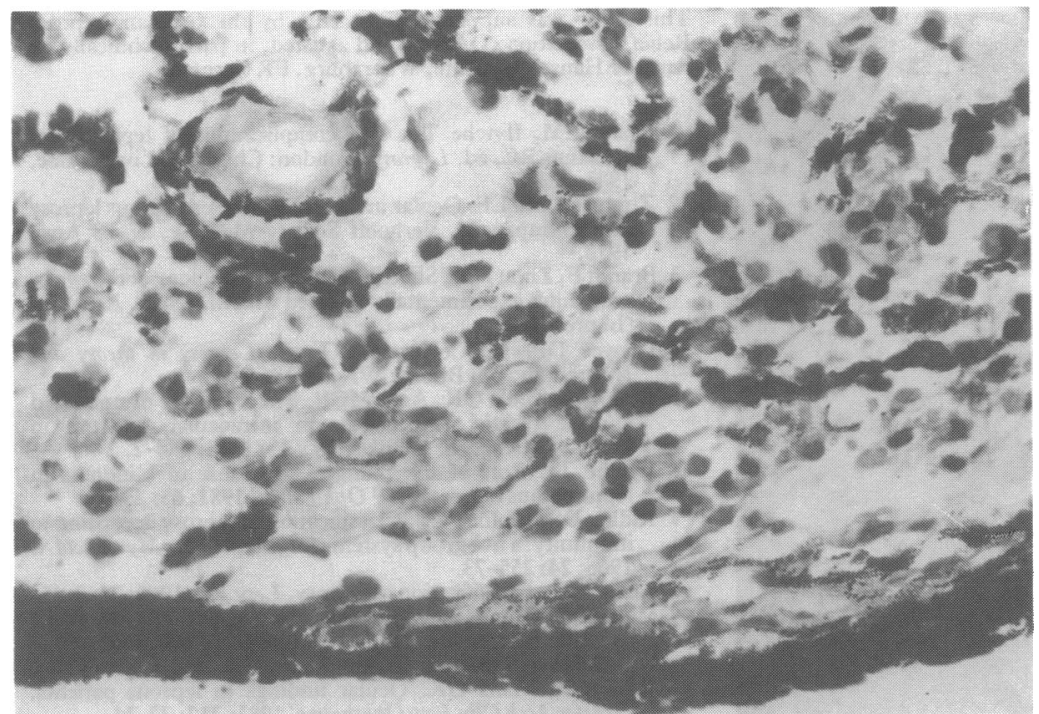

Figure 4: Lymphocytes, plasma cells, and macrophages infiltrate the matrix of the iris. ( $H$ and $E, \times 817$.)

The neovascularisation observed on the anterior surface of the iris could be due to chronic inflammation, as also the fibrous membrane formed behind the iris.

Amyloid deposits were not detected in any of our specimens. The five specimens of iris in which the presence of AFB was revealed were from lepromatous patients who were, with one exception, found to have posterior synechiae preoperatively. These AFB-containing specimens also showed slight, moderate, or heavy cellular infiltrations with lymphocytes, mast cells mostly associated with macrophages, neutrophils and eosinophils. The histology seen in our specimens is not of a granuloma but of a non-granulomatous inflammation. The fact that only five specimens out of $49(10 \%)$ were found to have AFB can perhaps be explained by the hypothesis that not all 49 eyes operated on had posterior synechiae, evidence of severe and chronic iritis in the past, and that the iritis tissue obtained during cataract surgery is usually a very

Figure 5: Russell's body (arrow) among the infiltrated inflammatory cells in the iris. ( $H$ and $E, \times 400$.)

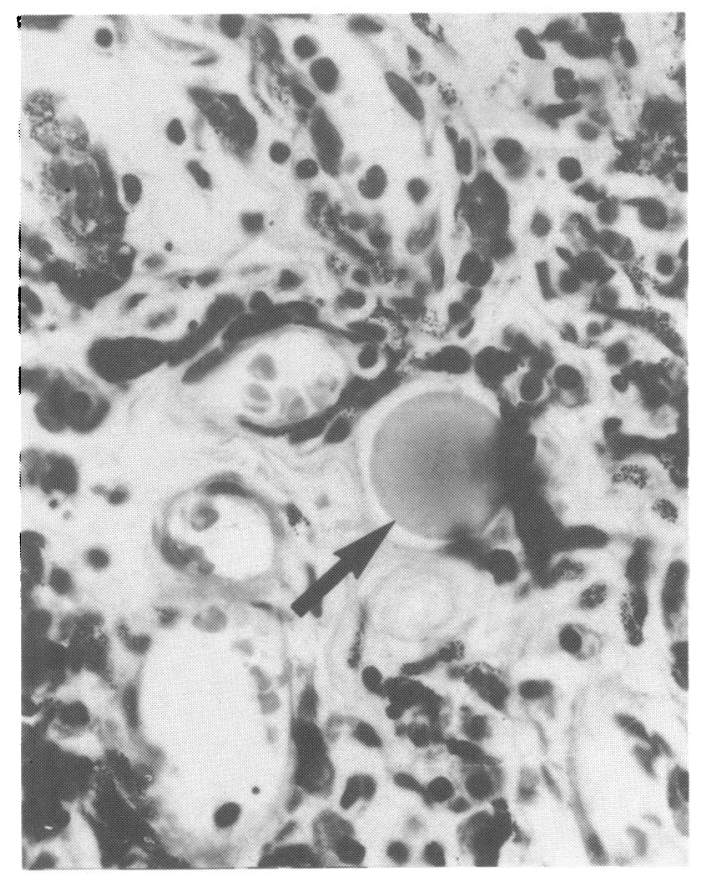

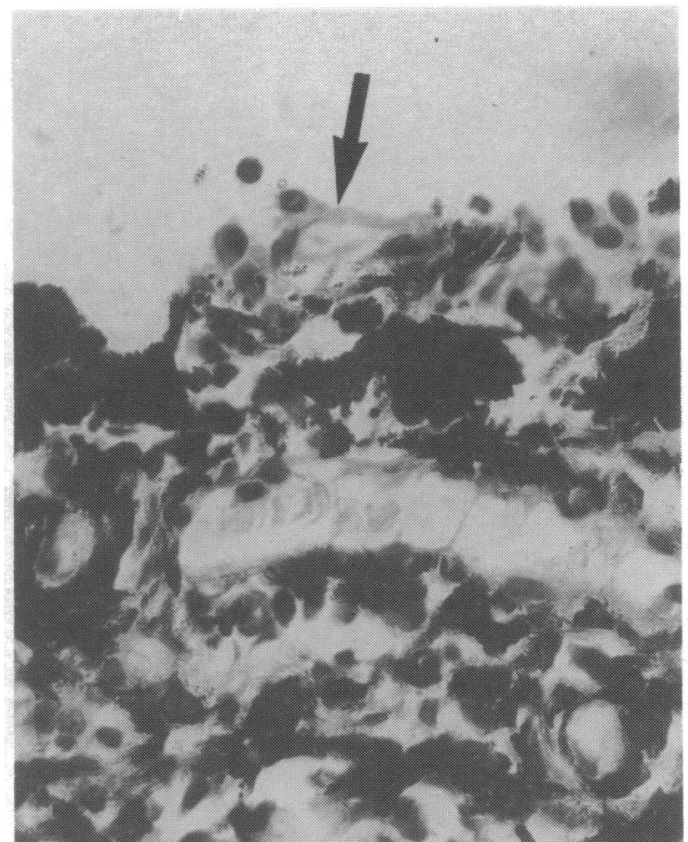

Figure 6: A small blood vessel (arrow) protrudes forwards from the anterior surface of the iris; neovascularisation of iris. $(H$ and $E, \times 1000$.)

small specimen. Consequently the specimen obtained may have just missed the AFB lying in the tissue.

Like others who have found AFB in different tissues, as in nerve ${ }^{17}$ or skin ${ }^{18}$ of dapsone treated leprous patients, we cannot say whether the AFB detected in the five specimens of iris tissue were viable or not at the time of surgery. But if the bacilli were surviving at the time of their removal from a living eye in patients showing an inactive state of the disease following years of treatment with dapsone, it can be conjectured that either the dapsone has a poor intraocular penetration or the bacilli have developed resistance to the drug. Thus it remains a matter of great concern if the systemic relapse of dapsone treated and apparently cured leprous patients is due to the dissemination of surviving and probably dapsone resistant AFB from within the eye.

It has been seen that iritis occurs many years after clinical inactivation of the disease by treatment in some patients. This iritis may perhaps be the first sign of a systemic relapse of the disease after long quiescence. ${ }^{19}$ But, even if the AFB had become inactive or fragmented, iritis might also occur or recur when the antigen undergoes any reaction with antibodies, resulting in the clinical picture of iritis.

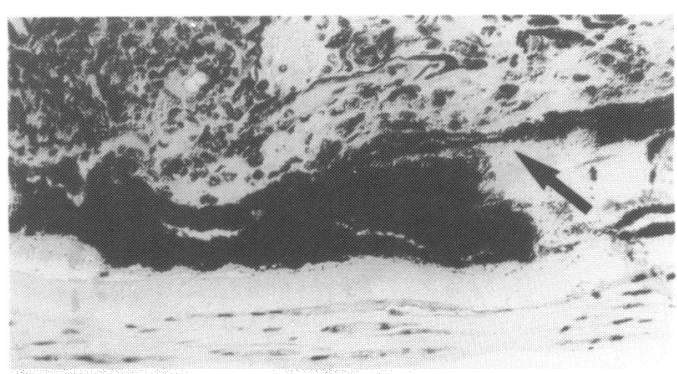

Figure 7: The pigment epithelium is atrophic (arrow) and the dilator muscle is beyond recognition. In front of the adherent lens capsule the formed fibrous membrane is distinct. $(H$ and $E, \times 285$.) 


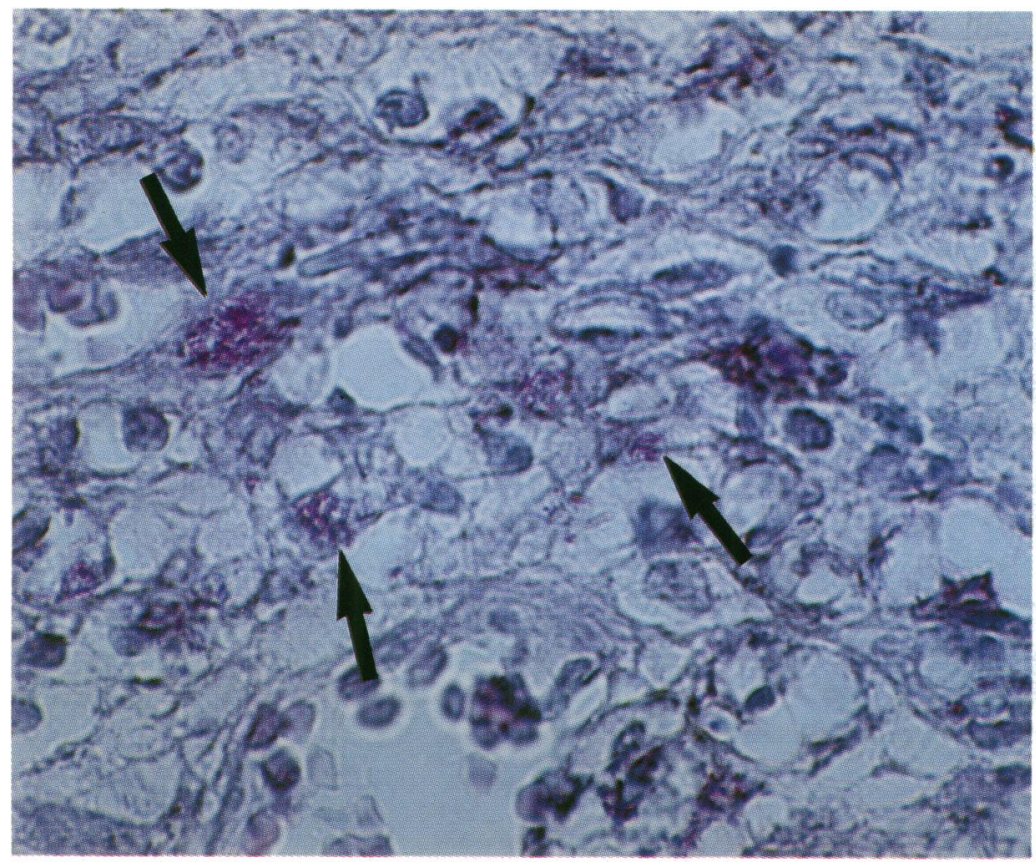

Figure 8: Several acid fast bacilli (arrows) in the wall of a blood vessel. $(F F, \times 1000$.)

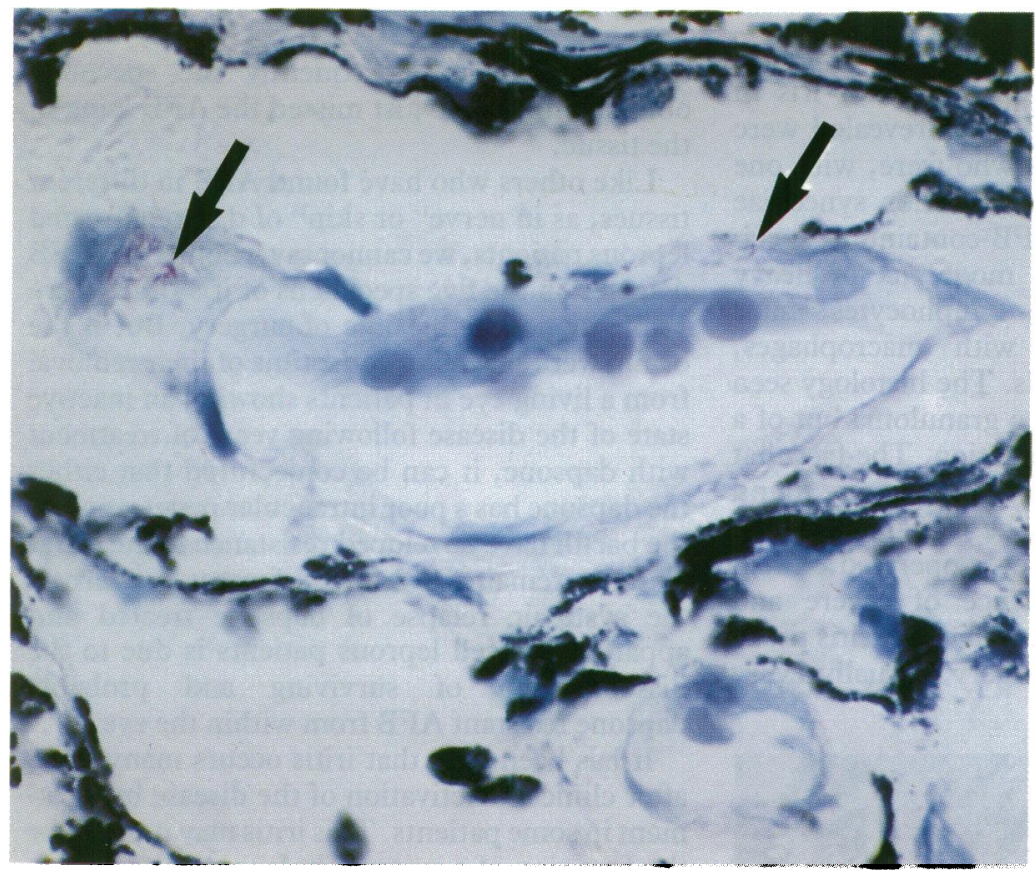

Figure 9: Many acid fast bacilli (arrows) in the stroma cells. (FF after depigmentation, $\times 1000$.)
This study was supported financially by the German Leprosy Relief Association (DAHW) and assisted, in part, technically by Amauer Hansen Institute, Wuerzburg, FR Germany.

1 Brand EM, ffytche TE. Eye complications of leprosy. In: Hastings RC, ed. Leprosy. London: Churchill-Livingstone, 1985: 227 .

2 Zimmermann LE. Ocular involvement in lepromatous leprosy in a chimpanzee. Verhoeff Society Meeting, 27-28 April

3 Brandt F, Zhou HM, Shi ZR, et al. The pathology of the eye in armadillos experimentally infected with $M$. leprae. Lepr Rev (In press)

4 Choyce DP. In: Cochrane RG, ed. Leprosy in theory and practice. 2nd ed. Bristol: Wright, 1964.

5 Brandt F, Malla OK, Anten JGF. The influence of untreated chronic plastic iridocyclitis on intraocular pressure in leprosy patients. Brf Ophthalmol 1981; 65: 240-2.

6 ffytche TJ. Role of iris changes as a cause of blindness in lepromatous leprosy. Br f Ophthalmol 1981; 65: 231-9.

7 Ridley DS, Jopling WS. Classification of leprosy according to immunity: a five group system. Int $\mathcal{F}$ Lept Other Mycobact Dis 1966; 24: 255-73.

8 Leiker DL. Classification of leprosy, Lepr Rev 1966; 37: 7-15.

9 Malla OK, Brandt F, Anten JGF. Ocular findings in leprosy patients in an institution in Nepal (Khokana). Br $\mathcal{F}$ patients in an institution

10 Brandt F, Malla OK. Ocular findings in leprous patients. Graefes Arch Clin Exp Ophthalmol 1981; 217: 27-34.

11 Brandt F, Kist P, Wos J. Augenbefunde bei Lepra. Klin Monatsbl Augenheilkd 1981; 178: 55-8.

12 Brandt F, Kalthoff PG. The incidence of lagophthalmus and posterior synechiae of the iris during chemotherapy of leprosy (Morbus Hansen). Trop Med Parasitol 1983; 34:

13 Brandt F, Kampik A, Malla, OK, Pokharel RP, Wos J. Blindness from cataract formation in leprosy. Dev Ophthalmol 1983; 7: 1-12.

14 Shrestha HG, Brandt F. Histological findings in blind, enucleated eye balls of leprosy patients. F Nepal Med Assoc 1989; 27: 101-5.

15 Brandt F, Shrestha KB. Über den Wandel von ophthalmologischen Befunden bei Morbus Hansen unter otherapie. Fortschr Ophthalmol 1983; 79: 455-7.

16 Syryawanshi N, Richard Cataract surgery on leprosy patients. Int $\mathcal{F}$ Lepr Other Mycobact Dis 1988; 56: 238-41.

17 Theuvenet W. Nerve decompression in leprosy. International Leprosy Congress, The Hague, 1988.

18 Wabitsch KR, Meyers WM. Histopathologic observations on the persistence of Mycobacterium leprae in the skin of multibacillary leprosy patients under chemotherapy. Lepr Rev 1988; 59: 341-6.

19 Brandt F, Adiga RB, Pradhan H. Lagophthalmus und hintere Synechien der Iris bei der Behandlung der Lepra mit Diamino-diphenyl-sulfon. Klin Monatsbl Augenheilkd 1984; 184: $28-31$. 